\title{
Bazı Yeni 2,5-Disübstitüe Benzoksazol Türevlerinin Sentezi, Antimikrobiyal Aktivite, Moleküler Doking ve DFT Çalışmaları
}

\author{
Meryem Erol $^{1 *}$, İsmail Çelik ${ }^{2}$, Gülcan Kuyucuklu ${ }^{3}$ \\ ${ }^{1}$ Erciyes University, Faculty of Pharmacy, Department of Pharmaceutical Chemistry, Kayseri, Turkey (ORCID: 0000-0001-5676-098X), eczacimeryem@gmail.com \\ ${ }^{2}$ Erciyes University, Faculty of Pharmacy, Department of Pharmaceutical Chemistry, Kayseri, Turkey (ORCID: 0000-0002-8146-1663), ismailcelik@erciyes.edu.tr \\ ${ }^{3}$ Trakya University, Faculty of Medicine, Department of Medical Microbiology, Edirne, Turkey (ORCID: 0000-0003-1596-1659), gulcankuyucuklu@gmail.com
}

(İlk Geliş Tarihi 15 Haziran 2021 ve Kabul Tarihi 24 Eylül 2021)

(DOI: $10.31590 /$ ejosat.952738)

ATIF/REFERENCE: Erol, M., Çelik, İ. \& Kuyucuklu, G. (2021). Bazı Yeni 2,5-Disübstitüe Benzoksazol Türevlerinin Sentezi, Antimikrobiyal Aktivite, Moleküler Doking ve DFT Çalışmaları. Avrupa Bilim ve Teknoloji Dergisi, (27), 605-614.

$\ddot{O} z$

Bu çalışmada 6 adet orijinal 2,5-disübstitüe benzoksazol türevi sentezlendi ve yapılar1 ${ }^{1} \mathrm{H}-\mathrm{NMR},{ }^{13} \mathrm{C}-\mathrm{NMR}$ spektrokopisi ve HRMS ile aydınlatıldı. Sentezlenen bileşiklerin mikrodilüsyon tekniği ile çeşitli Gram (+), Gram (-) bakteri, mantar ve bunların izolatlarına karşı antimikrobiyal aktiviteleri incelendi. Test edilen benzoksazol türevlerinin antimikrobiyal aktiviteleri genel olarak referans ilaçlara göre daha zayıf olmakla birlikte; en iyi aktiviteyi C. albicans izolatına karşı MiK: $16 \mu \mathrm{g} / \mathrm{mL}$ ile C1, C5 ve C6 türevleri gösterdi. Bileşiklerin moleküler doking çalışması gerçekleştirildi ve $C$. albicans izotına karşı en etkili bileşiklerden biri olan $\mathbf{C 5}$ 'in (doking skoru en düşük olan) 2D/3D protein-ligand etkileşimleri gösterildi. Ayrıca tüm bileşiklerin HOMO-LUMO enerjileri ve bu enerjilerden elde edilen

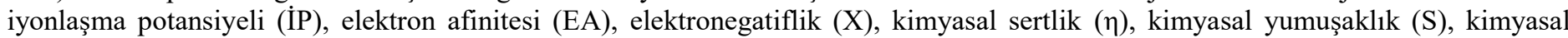
potansiyel $(\mu)$ ve elektrofilik indeks $(\omega)$ gibi diğer elektronik parametreleri hesaplandı. C1, C5 ve C6'nın HOMO-LUMO diyagramı, moleküler elektrostatik potansiyel analizi ve optimize edilmiş moleküler yapıları da görsel olarak sunuldu.

\section{Synthesis, Antimicrobial Activity, Molecular Docking and DFT Studies of Some New 2,5-Disubstituted Benzoxazole Derivatives}

\begin{abstract}
In this study, 6 original 2,5-disubstituted benzoxazole derivatives were synthesized and their structures were elucidated by ${ }^{1} \mathrm{H}-\mathrm{NMR}$, ${ }^{13} \mathrm{C}-\mathrm{NMR}$ spectroscopy, and HRMS.Their antimicrobial activities against various Gram (+), Gram (-) bacteria, fungi, and their isolates were investigated by microdilution technique. Although antimicrobial activities of tested benzoxazole derivatives were generally weaker than reference drugs; C1, C5 and C6 derivatives showed the best activity against C. albicans isolate with MIC: $16 \mu \mathrm{g} / \mathrm{mL}$. Molecular docking study of the compounds was carried out and 2D/3D protein-ligand interactions of $\mathbf{C 5}$ (the lowest docking score), one of the most effective compounds against $C$. albicans isolate, were demonstrated. In addition, HOMO-LUMO energies of all compounds and electronic parameters such as ionization potential (IP), electron affinity (EA), electronegativity (X), chemical hardness ( $\eta$ ), chemical softness $(\mathrm{S})$, chemical potential $(\mu)$ and electrophilic index $(\omega)$ obtained from these energies were calculated. The HOMO-LUMO diagram, molecular electrostatic potential analysis, and optimized molecular structures of $\mathbf{C 1}, \mathbf{C 5}$, and $\mathbf{C 6}$ were also presented visually.
\end{abstract}

Keywords: Benzoxazole, Synthesis, Antimicrobial activity, DFT, Molecular docking.

* Corresponding Author: eczacimeryem@gmail.com 


\section{Giriş}

Bakteri ve mantarların neden olduğu bulaşıcı hastalıklar halen halk sağlı̆̆ına yönelik en önemli tehditlerden birisidir. Özellikle metisiline dirençli Staphylococcus aureus (MRSA), vankomisine dirençli Enterococcus faecalis (VREF) ve flukonazole dirençli C. albicans gibi yaygın ilaç direnci çağımızın en ciddi sorunları arasında yer almaktadır (Aslam ve ark., 2018; De Oliveira ve ark., 2020; Ventola, 2015). Klinikte kullanılan birçok antimikrobiyal ilaç olmasına rağmen mikroorganizmalar bu ilaçlara karşı hızla direnç geliştirdiği için kısa sürede daha az etkili hale gelmektedir. Bugün; ilaca bağlı veya mikroorganizma kaynaklı direnç gelişmeleri, uygun olmayan tedavi yöntemleri, yalnızca semptomları ortadan kaldırmak için yazılan reçeteler ve hastaların tedaviyi yarıda bırakması bulaşıcı hastalıklarla mücadeleyi zorlaştırmaktadır. Antimikrobiyallere direnç; daha yüksek tıbbi maliyetlere, tedavi başarısızlığına, artan mortalite ve morbidite oranına, hastanede daha uzun kalış süresine ve artan sakatlığa yol açmaktadır. Organ nakli, kanser tedavisi, diyabet ve cerrahi operasyonlar gibi birçok tıbbi işlem, enfeksiyonların önlenmesi ve tedavisi için etkili antimikrobiyaller olmadan çok daha riskli hale gelmektedir (Abushaheen ve ark., 2020; Christaki ve ark., 2020; French, 2010). Bu durum, yeni ilaç geliştirme çalışmalarının ne kadar önemli olduğunu ortaya çıkarmakta ve araştırmacıları daha etkili antimikrobiyal ilaçlar tasarlamaya ve sentezlemeye yönlendirmektedir.

Benzoksazol halka sisteminin açık kimyasal yapısı, nükleik asit yapısındaki adenin ve guanin bazlarının yapısal izosterleridir (Şekil 1) ve kemoterapötik aktivitelerini nükleik asit sentezini inhibe ederek gösterdiği düşünülmektedir (Oehlers ve ark., 2004). $\mathrm{Bu}$ yaklaşım, benzoksazol türevlerine olan ilgiyi daha da artırmaktadır.

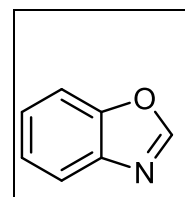

(a)<smiles>Nc1ncnc2[nH]cnc12</smiles>

(b)<smiles>NC1=NC2NC=NC2C(=O)N1</smiles>

(c)
Şekil 1. Benzoksazol (a), adenin (b) ve guanin (c) halkalarl

Son çalışmalarda benzoksazol halkasına sahip birçok doğal ve sentetik ürün, antimikrobiyal (Taşc1 ve ark., 2018), antiparkinson (Benazzouz ve ark., 1995), antihipertansif (Wu ve ark., 2018), antikanser (Osmaniye ve ark., 2021), antioksidan (Kashid ve ark., 2019), antikonvülsan (Song ve ark., 2019) ve anti-alzheimer (Temiz-Arpaci ve ark., 2016) gibi çok çeşitli farmakolojik özellikler sergilemektedir. Daha önceki yapılan çalışmalarda, benzoksazol halkasının 2. pozisyonda $p$ (sübstitüefenil/benzil) ve 5. pozisyonda amid yan zincirine bağl1 6 üyeli halkalar sentezlenmiş ve türevler arasında MRSA'ya karşı gentamisin kadar etkili bileşikler gözlenmiş; ayrıca MRSA'ya karşı yapılan kantitatif yapı-etki çalışması ile de yapıda piperazin grubu varlığının aktiviteyi olumlu etkilediği belirlenmiştir (Arisoy, M. ve ark., 2008; Temiz-Arpacı ve ark., 2005). Bu verilerden hareketle bu çalışma kapsamında genel yapısı 2-( $p$ metil/etilfenil)-5-(2-(4-sübstitüepiperazin-1-il) asetamido)benzoksazol olan bazı yeni bileşikler sentezlendi (Şekil 2), yapıları ${ }^{1} \mathrm{H}-\mathrm{NMR},{ }^{13} \mathrm{C}-\mathrm{NMR}$ spektroskopisi ve HRMS ile aydınlatıldı. Mikrodilüsyon tekniği ile çeşitli Gram (+), Gram (-) bakteri, mantar ve bunların izolatlarına karşı antimikrobiyal aktiviteleri incelendi ve yapı-aktivite ilişkileri değerlendirildi. Ayrıca, bileşiklerin moleküler reaktivite analizi (HOMO-LUMO) ve bu analizden elde edilen diğer elektronik parametreler, moleküler elektrostatik potansiyel (MEP) analizi ve geometri optimizasyonu DFT/B3LYP teorisi ve 6-311G+ $(\mathrm{d}, \mathrm{p})$ baz seti ile hesapland1, ve sonuçlar görüntülendi.

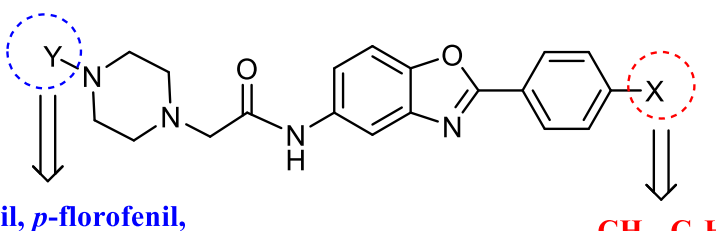

benzoil, $p$-florofenil, $p$-klorofenil, $p$-nitrofenil

$$
\mathrm{CH}_{3}, \mathrm{C}_{2} \mathrm{H}_{5}
$$

Şekil 2. Sentezlenen yeni benzoksazol türevleri

\section{Materyal ve Metot}

\subsection{Kimya}

Kimyasallar ve çözücüler Sigma Aldrich, Merck, Riedel de Haen ve Fluka'dan satın alındı ve daha fazla saflaştırılmadan kullanıldı. Erime noktaları Electrothermal 9100 (Varian, Palo Alto, CA) cihazı ile belirlendi ve sonuçlar düzeltilmeden verildi. ${ }^{1} \mathrm{H}-\mathrm{NMR}$ ve ${ }^{13} \mathrm{C}$ NMR spektrumları, Varian Mercury $400 \mathrm{MHz}$ Yüksek Performanslı Dijital FT-NMR spektrometresi (Palo Alto, $\mathrm{CA}, \mathrm{ABD})$ ile alındı ve çözücü olarak dimetilsülfoksit-d $\mathrm{d}_{6}$ (DMSO-d 6 ) kullanıldı. M+1 pikleri, Shimadzu LC/MS ITTOF sistemi (Shimadzu, Tokyo, Japonya) ile belirlendi.

\subsubsection{2-(p-Metil/Etilfenil)-5-(2-(4-sübstitülepiperazin-1- il)asetamido)benzoksazol Türevlerinin Sentezi}

İlk basamakta, 1 mmol 2,4-diaminofenol dihidroklorür ve 1 mmol $p$-metil/etil benzoik asit, polifosforik asit (PPA) katalizörlüğünde $160^{\circ} \mathrm{C}-190^{\circ} \mathrm{C}$ 'de yaklaşık 3 saat karıştırıldı. Reaksiyonun sonunda, reaksiyon içeriği buz üzerine döküldü ve \%10'luk $\mathrm{NaOH}$ çözeltisi, ortam alkali olana kadar ilave edildi. Çökelti süzüldü, etanol-su karışımından kristallendirildi ve kurutuldu. 2. Basamakta, $1 \mathrm{mmol} 2$-( $p$-metil/etilfenil)-5-amino benzoksazol (A1, A2) $20 \mathrm{ml}$ dietil eter içinde çözüldü. $2 \mathrm{mmol}$ $\mathrm{NaHCO}_{3} 10 \mathrm{ml}$ su içinde çözüldü. Eter ve su fazı, buz banyosu içinde manyetik karıștırıcıda karıștırılırken, 1 mmol 2kloroasetilklorür yavaş yavaş ilave edildi ve karıştırmaya gece boyunca devam edildi. Reaksiyonun sonunda oluşan çokelek süzüldü, etanol-su karışımından kristallendirildi ve kurutuldu. 3 . Basamakta, 1 mmol 2-(p-metil/etilfenil)-5-(2kloroasetamido)benzoksazol türevi bileşikler (B1, B2), $1 \mathrm{mmol}$ piperazin türevleri ile trietilamin (TEA) ve dimetilformamid (DMF) katalizörlüğünde oda sıcaklığında 24 saat reaksiyona bırakıldı. Reaksiyonun sonunda ortama su ilave edildi, ürün çökeltildi, daha sonra etanol-su karışımından kristallendirildi veya kolon kromatografisi metodu ile saflaştırıldı (mobil faz: etil asetat- $n$-heksan (1:1) ve sonuç ürünler elde edildi (C1-C6). 


\section{2-(p-Metilfenil)-5-(2-(4-(p-nitrofenilpiperazin-1-il)asetamido) benzoksazol (C1)}

Verim \%75, erime noktası: $200-202{ }^{0} \mathrm{C} .{ }^{1} \mathrm{H}-\mathrm{NMR} \delta \mathrm{ppm}(400$ MHz, DMSO-d 6 ): 9.99 (s, 1H, -NH), 8.17 (d, $J=1.9 \mathrm{~Hz}, 1 \mathrm{H}, \mathrm{Ar}-$ $\mathrm{H}), 8.06(\mathrm{~d}, J=2.1 \mathrm{~Hz}, 2 \mathrm{H}, \mathrm{Ar}-\mathrm{H}), 7.71(\mathrm{~d}, J=8.7 \mathrm{~Hz}, 1 \mathrm{H}, \mathrm{Ar}-\mathrm{H})$, 7.61 (s, 1H, Ar-H), 7.42 (d, $J=8.0 \mathrm{~Hz}, 3 \mathrm{H}, \mathrm{Ar}-\mathrm{H}), 7.04$ (d, $J=9.0$ $\mathrm{Hz}, 3 \mathrm{H}, \mathrm{Ar}-\mathrm{H}), 3.55$ (d, J = 9.6 Hz, 4H, (2)- $\left.\mathrm{CH}_{2}\right), 3.25$ (s, 2H, $\left.\mathrm{CH}_{2}\right), 2.69$ (d, $\left.J=5.0 \mathrm{~Hz}, 4 \mathrm{H},(2)-\mathrm{CH}_{2}\right), 2.41\left(\mathrm{~s}, 3 \mathrm{H},-\mathrm{CH}_{3}\right) .{ }^{13} \mathrm{C}-$ NMR $\delta$ ppm (100 MHz, DMSO-d $\left.{ }_{6}\right): 168.61,163.58,155.19$, $146.84,142.64,142.14,137.29,136.26,130.38,127.69,126.21$, $124.13,118.23,113.11,111.01,110.74,61.83,52.67,46.72$, 21.63. HRMS $(\mathrm{m} / \mathrm{z}):[\mathrm{M}+\mathrm{H}]^{+} \mathrm{C}_{26} \mathrm{H}_{25} \mathrm{~N}_{5} \mathrm{O}_{4}$ için hesaplanan: 472.19065; bulunan: 472.19945 .

\section{2-(p-Metilfenil)-5-(2-(4-benzoilpiperazin-1-il)asetamido) benzoksazol (C2)}

Verim \%50, erime noktası: $175-177^{\circ} \mathrm{C} .{ }^{1} \mathrm{H}-\mathrm{NMR} \delta \mathrm{ppm}(400$ MHz, DMSO-d 6 ): 9.97 (s, 1H, -NH), 8.15 (d, $J=2.0 \mathrm{~Hz}, 1 \mathrm{H}, \mathrm{Ar}-$ H), 8.07 (d, $J=8.0 \mathrm{~Hz}, 3 \mathrm{H}, \mathrm{Ar}-\mathrm{H}), 7.70(\mathrm{~d}, J=8.7 \mathrm{~Hz}, 1 \mathrm{H}, \mathrm{Ar}-\mathrm{H})$, $7.58(\mathrm{dd}, J=8.9,2.1 \mathrm{~Hz}, 1 \mathrm{H}, \mathrm{Ar}-\mathrm{H}), 7.47-7.42(\mathrm{~m}, 6 \mathrm{H}, \mathrm{Ar}-\mathrm{H})$, $3.72\left(\mathrm{~s}, 3 \mathrm{H},-\mathrm{CH}_{3}\right), 3.41$ (s, $\left.4 \mathrm{H},(2)-\mathrm{CH}_{2}\right), 3.22\left(\mathrm{~s}, 2 \mathrm{H},-\mathrm{CH}_{2}\right), 2.61$ $(\mathrm{d}, J=7.6 \mathrm{~Hz}, 1 \mathrm{H},-\mathrm{CH}), 2.40\left(\mathrm{~s}, 3 \mathrm{H},-\mathrm{CH}_{3}\right) .{ }^{13} \mathrm{C}-\mathrm{NMR} \delta \mathrm{ppm}$ (100 MHz, DMSO-d $_{6}$ : 169.43, 168.58, 163.56, 146.83, 142.59, $142.14,136.36,136.24,130.34,129.96,128.89,127.67,127.36$, 124.13, 118.24, 110.96, 110.77, 61.84, 53.00, 47.53, 21.62. HRMS (m/z): $[\mathrm{M}+\mathrm{H}]^{+}$için hesaplanan: $\mathrm{C}_{27} \mathrm{H}_{26} \mathrm{~N}_{4} \mathrm{O}_{3}$ : 455.20049; bulunan: 455.21061 .

\section{2-(p-Etilfenil)-5-(2-(4-benzoilpiperazin-1-il)asetamido) benzoksazol (C3)}

Verim \%45, erime noktas1: $190-192{ }^{0} \mathrm{C} .{ }^{1} \mathrm{H}-\mathrm{NMR} \delta \mathrm{ppm}(400$ MHz, DMSO-d $\left.\mathrm{d}_{6}\right): 9.97$ (s, 1H, -NH), 8.15 (d, $J=2.0 \mathrm{~Hz}, 1 \mathrm{H}, \mathrm{Ar}-$ H), 8.10 (d, $J=6.5 \mathrm{~Hz}, 1 \mathrm{H}, \mathrm{Ar}-\mathrm{H}), 7.74-7.67$ (m, 2H, Ar-H), $7.63-7.54(\mathrm{~m}, 1 \mathrm{H}, \mathrm{Ar}-\mathrm{H}), 7.45(\mathrm{~d}, J=6.4 \mathrm{~Hz}, 7 \mathrm{H}, \mathrm{Ar}-\mathrm{H}), 3.72$ $\left(\mathrm{s}, 3 \mathrm{H},-\mathrm{CH}_{3}\right), 3.22\left(\mathrm{~s}, 2 \mathrm{H},-\mathrm{CH}_{2}\right), 3.14-2.41\left(\mathrm{~m}, 6 \mathrm{H},(3)-\mathrm{CH}_{2}\right)$, $1.22\left(\mathrm{t}, J=7.5 \mathrm{~Hz}, 4 \mathrm{H},(2)-\mathrm{CH}_{2}\right) .{ }^{13} \mathrm{C}-\mathrm{NMR} \delta \mathrm{ppm}(100 \mathrm{MHz}$, DMSO-d $)_{6}: 169.43,168.59,163.56,148.68,146.86,142.15$, $136.37,136.25,129.97,129.18,128.90,127.78,127.36,124.38$, $118.25,110.98,110.79,61.84,53.35,40.59,28.63,15.63$. HRMS $(\mathrm{m} / \mathrm{z}):[\mathrm{M}+\mathrm{H}]^{+} \mathrm{C}_{28} \mathrm{H}_{28} \mathrm{~N}_{4} \mathrm{O}_{3}$ için hesaplanan: 469.21614; bulunan: 469.22469 .

\section{2-(p-Etilfenil)-5-(2-(4-(p-nitrofenilpiperazin-1-il)asetamido) benzoksazol (C4)}

Verim \%77, erime noktası: $195-197^{0} \mathrm{C} .{ }^{1} \mathrm{H}-\mathrm{NMR} \delta \mathrm{ppm}(400$ MHz, DMSO-d 6 ): 10.00 (s, 1H, -NH), 8.17 (s, 1H, Ar-H), $8.14-$ $8.03(\mathrm{~m}, 4 \mathrm{H}, \mathrm{Ar}-\mathrm{H}), 7.72(\mathrm{~d}, J=8.7 \mathrm{~Hz}, 1 \mathrm{H}, \mathrm{Ar}-\mathrm{H}), 7.61(\mathrm{~s}, 1 \mathrm{H}$, Ar-H), 7.46 (t, $J=6.0 \mathrm{~Hz}, 2 \mathrm{H}, \mathrm{Ar}-\mathrm{H}), 7.05$ (d, $J=9.0 \mathrm{~Hz}, 2 \mathrm{H}, \mathrm{Ar}-$ $\mathrm{H}), 3.57-3.52\left(\mathrm{~m}, 3 \mathrm{H},-\mathrm{CH}_{3}\right), 3.25\left(\mathrm{~s}, 2 \mathrm{H},-\mathrm{CH}_{2}\right), 2.74(\mathrm{~s}, 1 \mathrm{H},-$ $\mathrm{CH}), 2.70$ (t, J = 7.2 Hz, 6H, (3)- $\left.\mathrm{CH}_{2}\right), 1.23$ (t, $J=7.5 \mathrm{~Hz}, 3 \mathrm{H}$, $\mathrm{CH}_{2}$ ve $\left.-\mathrm{CH}\right) .{ }^{13} \mathrm{C}-\mathrm{NMR} \delta \mathrm{ppm}\left(100 \mathrm{MHz}, \mathrm{DMSO}-\mathrm{d}_{6}\right): 168.59$, 163.58, 155.17, 148.69, 146.86, 142.16, 137.30, 136.26, 129.18, $127.79,126.20,124.37,118.23,113.10,111.00,110.77,61.84$, 52.67, 46.73, 40.60, 40.39, 40.18, 39.97, 39.76, 39.55, 39.34, 28.63, 15.63. HRMS (m/z): $[\mathrm{M}+\mathrm{H}]^{+} \mathrm{C}_{27} \mathrm{H}_{27} \mathrm{~N}_{5} \mathrm{O}_{4}$ için hesaplanan: 486.20630; bulunan: 486.21535 .

\section{2-(p-Etilfenil)-5-(2-(4-(p-klorofenilpiperazin-1-il)asetamido) benzoksazol (C5)}

e-ISSN: 2148-2683
Verim \%70, erime noktasi: $200-202{ }^{0} \mathrm{C} .{ }^{1} \mathrm{H}-\mathrm{NMR} \delta \mathrm{ppm}(400$ MHz, DMSO-d $\left.\mathrm{d}_{6}\right)$ : 9.94 (s, 1H, -NH), $8.19-8.08$ (m, 3H, Ar-H), $7.71(\mathrm{~d}, J=8.7 \mathrm{~Hz}, 1 \mathrm{H}, \mathrm{Ar}-\mathrm{H}), 7.60(\mathrm{~d}, J=9.0 \mathrm{~Hz}, 1 \mathrm{H}, \mathrm{Ar}-\mathrm{H})$, 7.45 (d, $J=8.0 \mathrm{~Hz}, 2 \mathrm{H}, \mathrm{Ar}-\mathrm{H}), 7.23$ (d, $J=8.5 \mathrm{~Hz}, 2 \mathrm{H}, \mathrm{Ar}-\mathrm{H})$, 6.95 (d, $J=8.6 \mathrm{~Hz}, 2 \mathrm{H}, \mathrm{Ar}-\mathrm{H}), 3.22$ (d, $J=7.7 \mathrm{~Hz}, 6 \mathrm{H},(3)-\mathrm{CH}_{2}$ ), 2.69 (q, $\left.J=6.6,4.8 \mathrm{~Hz}, 6 \mathrm{H},(3)-\mathrm{CH}_{2}\right), 1.23(\mathrm{t}, J=7.6 \mathrm{~Hz}, 3 \mathrm{H}$, $\left.\mathrm{CH}_{3}\right) .{ }^{13} \mathrm{C}-\mathrm{NMR} \delta \mathrm{ppm}\left(100 \mathrm{MHz}, \mathrm{DMSO}-\mathrm{d}_{6}\right): 168.66,163.56$, $150.28,148.69,146.85,142.16,136.28,129.20,129.07,127.79$, $124.38,122.73,118.21,117.31,111.00,110.73,62.12,53.01$, 48.36, 28.63, 15.65. HRMS (m/z): $[\mathrm{M}+\mathrm{H}]^{+} \mathrm{C}_{27} \mathrm{H}_{27} \mathrm{ClN}_{4} \mathrm{O}_{2}$ için hesaplanan: 475.18225; bulunan: 475.19141

\section{2-(p-Etilfenil)-5-(2-(4-(p-florofenilpiperazin-1-il)asetamido) benzoksazol (C6)}

Verim \%65, erime noktası: $192-194^{\circ} \mathrm{C} .{ }^{1} \mathrm{H}-\mathrm{NMR} \delta \mathrm{ppm}(400$ MHz, DMSO-d 6 ): 9.96 (s, 1H, -NH), 8.17 (d, $J=2.0 \mathrm{~Hz}, 1 \mathrm{H}, \mathrm{Ar}-$ H), $8.11-8.08$ (m, 2H, Ar-H), $7.71(\mathrm{~d}, J=8.8 \mathrm{~Hz}, 1 \mathrm{H}, \mathrm{Ar}-\mathrm{H})$, $7.60(\mathrm{dd}, J=8.9,2.1 \mathrm{~Hz}, 1 \mathrm{H}, \mathrm{Ar}-\mathrm{H}), 7.45(\mathrm{~d}, J=8.3 \mathrm{~Hz}, 2 \mathrm{H}, \mathrm{Ar}-$ H), 7.05 (dd, $J=9.7,8.0 \mathrm{~Hz}, 2 \mathrm{H}, \mathrm{Ar}-\mathrm{H}), 6.99-6.93$ (m, 2H, Ar$\mathrm{H}), 3.23\left(\mathrm{~s}, 2 \mathrm{H},-\mathrm{CH}_{2}\right), 3.16\left(\mathrm{t}, J=4.9 \mathrm{~Hz}, 4 \mathrm{H},(2)-\mathrm{CH}_{2}\right), 2.70(\mathrm{t}$, $\left.J=5.8 \mathrm{~Hz}, 6 \mathrm{H},(3)-\mathrm{CH}_{2}\right), 1.22$ (t, $\left.J=7.6 \mathrm{~Hz}, 3 \mathrm{H},-\mathrm{CH}_{3}\right) .{ }^{13} \mathrm{C}-\mathrm{NMR}$ $\delta$ ppm $(100 \mathrm{MHz}$, DMSO-d 6 ): 168.69, 163.56, 148.70, 148.40, $146.84,142.16,136.29,129.21,127.79,124.38,118.20,117.63$, $117.56,115.82,115.61,111.01,110.71,62.16,53.18,49.32$, 28.63, 15.65. HRMS (m/z): $[\mathrm{M}+\mathrm{H}]^{+} \quad \mathrm{C}_{27} \mathrm{H}_{27} \mathrm{FN}_{4} \mathrm{O}_{2} \quad$ için hesaplanan: 459.21180; bulunan: 459.22019

\subsection{Antimikrobiyal Aktivite Çalışmaları}

Escherichia coli ATCC 25922, Pseudomonas aeruginosa ATCC 27853, Staphylococcus aureus ATCC 29213, Enterococcus faecalis ATCC 29212 ve Candida albicans ATCC 1023 standart suşları ve klinik izolatları Trakya Üniversitesi Sağlık Araştırma ve Uygulama Merkezi'nden tedarik edildi. Test bileşiklerinin stok çözeltileri DMSO (Merck) içinde hazırlandı. Ampisilin fosfat tampon solüsyonunda hazırlandı ve diğer antibiyotik solüsyonları CLSI M100-S28 ve M27-A3 kılavuzlarına göre steril damıtılmış suda hazırlandı (CLSI, 2008; CLSI, 2018). Mueller Hinton Agar (MHA) (Merck), Mueller Hinton Broth (MHB) (Merck), Sabouraud Dekstroz Agar (SDA) (Merck), Sabouraud Liquid Medium (SLM) (Merck) ve L- ile RPMI-1640 besiyeri (Sigma) 3-[N-morfolino]-propansülfonik asit (MOPS) (Sigma) ile glutamin tamponlu pH 7, mikrobiyal kültürler için kullanıldı. Bakteriyel izolatlar, Mueller Hinton Agar (MHA) plaklarında alt kültürlendi ve gece boyunca $37^{\circ} \mathrm{C}^{\prime}$ de inkübe edildi ve C. albicans, Sabouraud Dextrose Agar (SDA) plaklarda $24-48$ saat $35^{\circ} \mathrm{C}$ 'de alt kültürlendi. Saf koloniler sırasıyla bakteri ve mantarlar için MHB ve SLM'ye aktarıldı. Gece boyunca uygun koşullarda inkübe edildi. İnkübasyondan sonra, aşılama için kullanılan bakteriyel süspansiyonlar, MacFarland 0.5 yoğunlukta $\left(10^{8} \mathrm{CFU} / \mathrm{mL}\right)$ taze kültürler seyreltilerek $10^{5} \mathrm{CFU} / \mathrm{mL}$ 'de hazırland. Mantar süspansiyonları da McFarland 0.5 yoğunluğuna göre hazırlandı ve 1:50 seyreltme ve ardından 1:20 oranında stok süspansiyonu $\left(2.5 \times 10^{3} \mathrm{CFU} / \mathrm{mL}\right)$ ile bir çalışma süspansiyonu yapıldı.

Duyarlılık testi, bakteriler için MHB ile ve mantarlar için 3[ $N$-morfolino]-propansülfonik asit (MOPS) ile L-glutamin tamponlu pH 7 ile RPMI-1640 ortamı ile gerçekleştirilmiştir. Yeni sentezlenen bileşiklerin ve standart ilaçların çözeltisi 512, 256, $128,64,32,16,8,4 \mu \mathrm{g} / \mathrm{mL}$ 'de hazırlandı ve her antimikrobiyal ajan için farklı stok konsantrasyonları, sırasıyla stok konsantrasyonları birçok kanallı pipetli mikrodilüsyon tepsisi. 
Seyreltmeden sonra, mikrodilüsyon tepsilerinin her bir oyuğuna $10 \mathrm{uL}$ bakteri veya mantar aşısı eklenmiştir. Tepsiler bakteriler için $37^{\circ} \mathrm{C}$ de ve mantarlar için $35^{\circ} \mathrm{C}$ de nemli bir odada inkübe edilmiş ve 24 saatlik inkübasyondan sonra MíK uç noktaları okunmuştur. Tüm organizmalar, deneylerin her seferinde üç kez test edildi.

\subsection{Moleküler Doking}

Moleküler doking çalışması Maestro 11.5 programı kullanılarak gerçekleştirildi. Tetrazol bazlı mantar önleyici ilaç adayı VT1161 (PDB ID: 5TZ1, 2.00 ^ çözünürlükte) ile kompleks halindeki $C$. albicans sterol 14-alfa demetilazın (CYP51) kristal yapısı, protein veri bankasından alınmıştır (https://www.rcsb.org/). Protein hazırlama, Protein Preparation Wizard kullanılarak yapıldı, hazırlama sırasında proteindeki su molekülleri silindi ve hidrojen atomları eklendi. Bileşiğin enerjisi, OPLS3 kuvvet alanı kullanılarak en aza indirildi. Ligandlar, OPLS3 kuvvet alanı kullanılarak LigPrep ile hazırlandı. Reseptör Grid Oluşturma programı ligandın herhangi bir atomuna tıklanarak çalıştırıldı ve varsayılan grid kutusu hazırlandı. Ligand, Standard Precision (SP) kullanılarak proteinden yapılmış ızgara kutusuna bağlandı. Sonuçlar Docking skoru, Glide gscore ve Glide emodel değerleri olarak sunuldu.

\subsection{DFT/B3LYP Hesaplamaları}

Bileşiklerin tüm teorik hesaplamaları; DFT/B3LYP yöntemi, 6-311G+ (d,p) baz seti ve Gaussian 09 paket programı kullanılarak yapıldı (Frisch, 2019), ve bileşiklerin HOMOLUMO enerjileri ve bu enerjilerden elde edilen diğer elektronik parametreler (iyonlaşma potansiyeli (İP), elektron afinitesi (EA), elektronegatiflik (X), kimyasal sertlik $(\eta)$, kimyasal yumuşaklık $(\mathrm{S})$, kimyasal potansiyel $(\mu)$ ve elektrofilik indeks $(\omega))$, MEP analizi ve geometri optimizasyonu sonuçları elde edildi. Sonuçlar GaussView 6.0.16 programı kullanılarak görselleştirildi (GaussView, 2016).

\subsection{In silico ADME Tahmini}

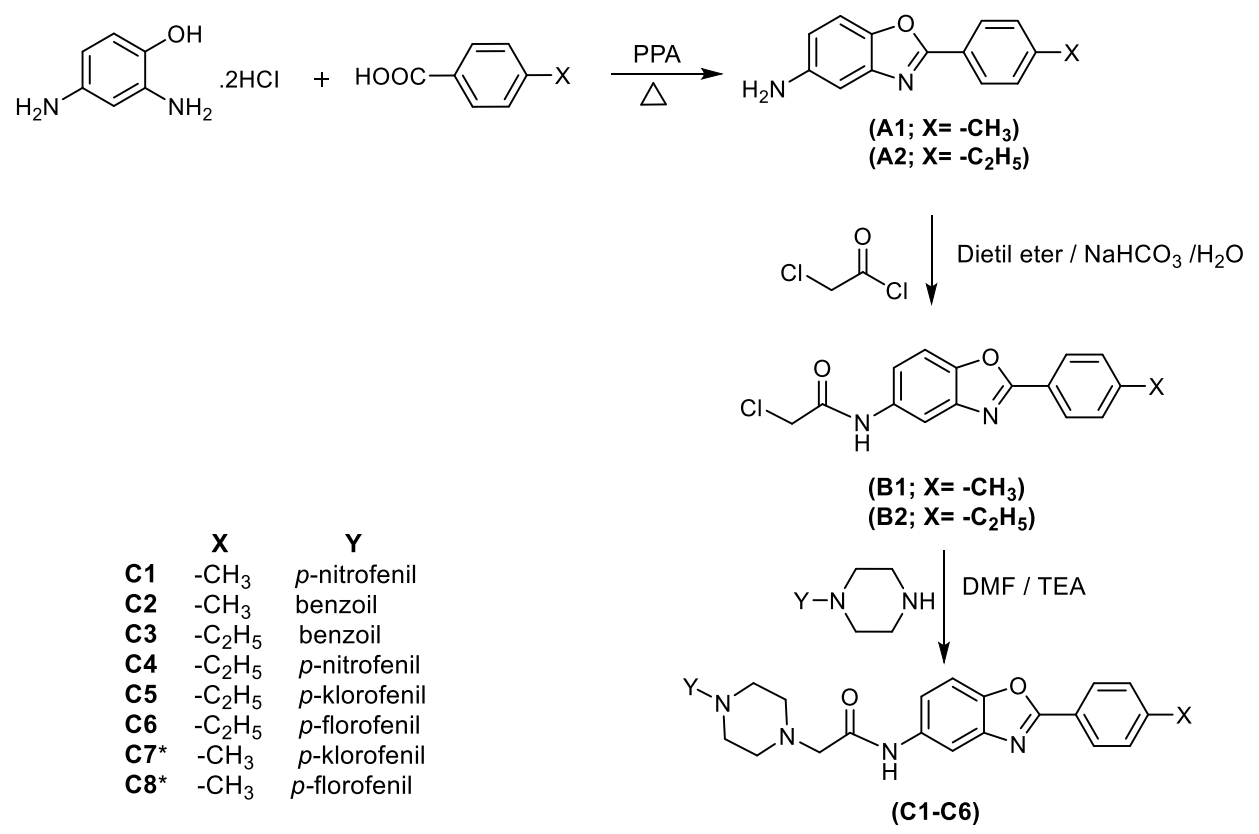

Molinspirasyon yazılım programı kullanılarak sentezlenen bileşiklerin log P, TPSA, nrotb, moleküler ağırlık ve hidrojen bağı verici-reseptör sayısı gibi çeşitli farmakokinetik parametre değerleri hesaplandı (Cheminformatics, 2018).

\section{Araştırma Sonuçları ve Tartışma}

\subsection{Kimya}

Bu çalışmada, 2-(p-Metil/etilfenil)-5-(2-(4sübstitüepiperazin-1-il)asetamido)benzoksazol serisi Şekil 3 'te gösterildiği gibi literatürde verilen yöntemler kullanılarak sentezlendi (Taşcı ve ark., 2018; Erol ve ark., 2020; Erol ve ark., 2021). Sonuç ürünlerin genel yapısı incelendiğinde, benzoksazol halkasının 2. pozisyonunda $p$-metil/etilfenil grubu ve 5 . pozisyonundaki asetamido grubuna bağlı $p$-sübstitüe piperazin türevleri vardır. $\mathrm{Bu}$ türevlerin sentezinde 2,4-diaminofenol dihidroklorür, PPA katalizörü altında uygun sıcaklık ve zamanda $p$-metil/etil benzoik asitler ile reaksiyona sokuldu (A1 ve A2). Elde edilen ürünler daha sonra benzoksazol yapılarının 5. pozisyonunun amidifikasyonlarını gerçekleştirmek için kloroasetil klorür ile muamele edildi (B1 ve B2). Son aşamada, B1 ve B2'nin $p$-sübstitüe piperazin türevleri ile reaksiyonu sonucunda hedef bileşikler elde edildi. Sentez işlemleri sırasında reaksiyon ortamı İnce Tabaka Kromatografisi (ITK) ile kontrol edildi ve bileşikler, sentez yöntemlerinde belirtildiği gibi saflaştırıldı (C1-C6). Sentezlenen tüm bileşikler orjinaldir. Benzoksazol halkasının 2. konumunda $p$-metilfenil ve 5 . konumunda amid yapısına bağlı $p$-florofenil piperazin ve $p$ klorofenil piperazin taşıyan türevler (C6 ve C7) orjinal olmadığ için sentezlenen türevler arasında bulunmamaktadır. Sonuç bileşiklerin yapılar $1{ }^{1} \mathrm{H}-\mathrm{NMR},{ }^{13} \mathrm{C}-\mathrm{NMR}$ spektroskopisi ve HRMS ile teyit edildi.

Nihai bileşiklerin spektroskopik verilerine göre, ${ }^{1} \mathrm{H}-\mathrm{NMR}$ spektrumlarında, NH protonlarının sinyali tekli yayvan pikler olarak 9.94-10.00 ppm'de göründü. Ayrıca aromatik protonlar 6.93-8.19 ppm ve alifatik protonlar 1.22-3.72 ppm arasındayd. Ayrıca bileşiklerin ${ }^{13} \mathrm{C}$-NMR spektrumları yapılarıyla uyumluydu ve bileşiklerin HRMS'si formülleriyle uyumlu olarak bir $[\mathrm{M}+\mathrm{H}]^{+}$ piki gösterdi.

Şekil 3. C1-C6'nın genel sentez yöntemi (* : Arisoy ve ark., 2014) 


\subsection{Antimikrobiyal Değerlendirme}

Bileşiklerin ve referans ilaçların antimikrobiyal aktivite sonuçları Tablo 1'de verilmiştir. Orjinal olmayan iki bileşiğin antimikrobiyal aktiviteleri literatürde daha önce verilmiştir (Arisoy ve ark., 2014). Sentezlenen bileşiklerin ve referans ilaçların MİK değerleri incelendiği zaman referans ilaçların genel olarak daha iyi antimikrobiyal aktivite gösterdiği gözlenmiştir. Sentezlenen benzoksazol türevlerinin $S$. aureus'a ve MRSA'ya karşı aktivitesi referans ilaçlara kıyasla etkisiz olarak gözlenmiştir. E. faecalis'e karşı aktivitesi incelendiğinde en iyi aktiviteyi $64 \mu \mathrm{g} / \mathrm{mL}$ ile $\mathbf{C 1}, \mathbf{C} 4$ ve $\mathbf{C 5}$ göstermiş olsa bile, yine de referans bileşiklerin sentezlenen benzoksazol türevlerinden daha etkili olduğu gözlenmiştir. Genel olarak bileşikler; E. coli, P. aeruginosa ve izolatlarına karşı zayıf antimikrobiyal etkiye sahip olduğu gözlemlenmiştir. Bileşiklerin $C$. albicans'a karşı antifungal aktiviteleri $64-128 \mu \mathrm{g} / \mathrm{mL}$ arasında değişirken; $C$. albicans izolatına karşı, C1, C5 ve C6, MİK: $16 \mu \mathrm{g} / \mathrm{mL}$ ile flukonazole yakın bir aktivite göstermiştir.Benzoksazol halkasının 2. ve 5. konumunda yaplan değişiklikler antimikrobiyal aktivitede anlamlı değişikliklere neden olmamıştır.

Tablo 1. C1-C6 ve referans ilaçların gözlenen in vitro antimikrobiyal MiK değerleri $(\mu \mathrm{g} / \mathrm{mL})$

\begin{tabular}{|c|cccc|ccccc|c|}
\hline \multirow{2}{*}{ Bileşik No } & \multicolumn{4}{|c|}{ Gram-pozitif bakteri } & \multicolumn{3}{c|}{ Gram-negatif bakteri } & \multicolumn{2}{c|}{ Mantar } \\
\cline { 2 - 10 } & S.a & S.a.* & E.f. & E.f* & E.c. & E.c.* & P.a. & P.a.* & C.a. & C.a.* \\
\hline C1 & 256 & 256 & 64 & 128 & 256 & 256 & 128 & 128 & 128 \\
C2 & 256 & 256 & 128 & 256 & 256 & 256 & 128 & 128 & 128 \\
C3 & 256 & 256 & 128 & 256 & 256 & 256 & 128 & 128 & 128 & 128 \\
C4 & 256 & 256 & 64 & 256 & 128 & 256 & 128 & 128 & 64 & 128 \\
C5 & 256 & 256 & 64 & 256 & 256 & 256 & 128 & 128 & 128 \\
C6 & 256 & 256 & 128 & 256 & 256 & 256 & 128 & 128 & 128 & 16 \\
Ampisilin & 2 & $>16$ & 2 & $>16$ & 8 & $>16$ & - & - & - & - \\
Vancomisin & 2 & 2 & 1 & 8 & - & - & - & - & - \\
Gentamisin & 0.25 & $>16$ & - & - & 0.5 & $>8$ & 0.5 & $>8$ & - & - \\
Siprofloksasin & 0.5 & $>16$ & 2 & $>4$ & 0.0156 & $>2$ & 0.125 & $>2$ & - & - \\
Sefotaksim & 1 & $>16$ & - & - & 0.125 & $>8$ & 8 & - & - & - \\
Flukonazol & - & - & - & - & - & - & - & - & 0.125 & $>4$ \\
Amfoterisin B & - & - & - & - & - & - & - & - & 0.5 & 0.5 \\
\hline
\end{tabular}

S.a.: Staphylococcus aureus ATCC 29213; S.a.*: S. aureus izolat1 (MRSA); E.f: Enterococcus faecalis ATCC 29212; E.f *: E. faecalis izolatı (Vankomisine dirençli -VREF); E.c .: E. coli ATCC 25922; E.c.*: E. coli izolatı (geniş spektrumlu $\beta$-laktamaz enzimi içerir); P.a.: Pseudomonas aeruginosa ATCC 27853; P.a.*: P. aeruginosa izolatı (gentamisin dirençli); C.a: Candida albicans ATCC 10231; C. a. *: Candida albicans izolatı. E. coli izolatı siprofloksasine dirençlidir. Geniş spektrumlu $\beta$-Laktamaz Enzimi (ESBL) içerir ve oksiiminobetalaktam antibiyotiklere dirençlidir. P. aeruginosa izolatı siprofloksasin ve ampisiline dirençlidir. E. faecalis izolatı vankomisine (VREF) dirençlidir. S. aureus izolatı MRSA'dır (tüm $\beta$-laktam antibiyotiklere dirençlidir). - : Belirlenmemiştir.

\subsection{Moleküler Doking Çalışması}

Sentezlenen bazı türevler, C. albicans izolatına karşı referans ilaçlara yakın aktivite sergilemiştir. C. albicans'taki direnç mekanizması, lanosterol demetilaz (Erg11p) ve ergosterol biyosentezindeki bir değişiklik olabilir (Kontoyiannis ve Lewis, 2002). Bu yüzden sterol 14 $\alpha$-demetilaz (CYP51) proteini üzerine (PDB: 5TZ1) odaklandık. Tüm bileşiklerin hesaplanan Docking skoru, Glide gscore ve Glide emodel skorları Tablo 2'de verilmiştir. Buna göre, elde edilen skorlar ile antimikrobiyal aktivite arasında orta derecede bir ilişki bulunmuştur.

Antimikrobiyal aktivite sonuçlarına göre C. albicans izolatına karşı en aktif bileşiklerden biri olan C5'in $2 \mathrm{D}$ ve $3 \mathrm{D}$ etkileşimleri gösterildi. C5 aynı zamanda en düşük doking skoruna sahipti. $\mathrm{Bu}$ bölgede benzoksazol halkasının 5 . pozisyonundaki asetamido grubunun azotu, MET508 ile $2.30 \AA$ uzunluğunda hidrojen bağı oluştururken; ayrıca TYR118,
HEM601, LEU121, PHE228, PRO230, ILE379, VAL509, TYR05, GLY65 ile hidrofobik etkileşimler oluşturmuştur. Bileşiklerin CYP51 (5TZ1) aktif bölgesindeki aminoasit etkileşimleri Tablo 3'de ve C. albicans izolatına karşı en aktif olan C1, C5 ve C6'nın 2D ve 3D görsel diyagramı Şekil 4'te verilmiştir.

Tablo 2. Bileşiklerin Hesaplanan Doking skoru, Glide gscore ve Glide emodel değerleri

\begin{tabular}{|c|ccc|}
\hline Bileşik & Doking skor & Glide GScore & Glide emodel \\
\hline C1 & -7.709 & -7.920 & -85.082 \\
C2 & -8.839 & -9.138 & -85.720 \\
C3 & -9.051 & -9.600 & -95.894 \\
C4 & -7.932 & -8.645 & -88.407 \\
C5 & $\mathbf{- 9 . 1 1 3}$ & $\mathbf{- 9 . 2 4 7}$ & $\mathbf{- 8 9 . 7 0 1}$ \\
C6 & -8.745 & -8.869 & -89.417 \\
\hline
\end{tabular}


Tablo 3. Sentezlenen bileşikler ile CYP51 proteini arasındaki protein-ligand etkileşimleri (PDB ID: 5TZ1)

\begin{tabular}{cl}
\hline Bileşik & \multicolumn{1}{c}{ Protein-ligand etkileşimleri } \\
\hline C1 & TYR64, TYR118, PHE233, HIE377 \\
C2 & ALA61, TYR64, LEU87, TYR132, PRO230, MET508, HEM601 \\
C3 & ALA61, LEU87, TYR132, PRO230, PHE380, MET508, HEM601 \\
C4 & TYR118, ILE131, ILE304, PRO230, LEU376, HIS377, HEM601 \\
C5 & TYR64, TYR118, HEM601, MET508 \\
C6 & TYR64, TYR118, PHE233, MET508 \\
\hline *Koyu renk ile belirtilenler hidrojen bağıdır. \\
\hline
\end{tabular}

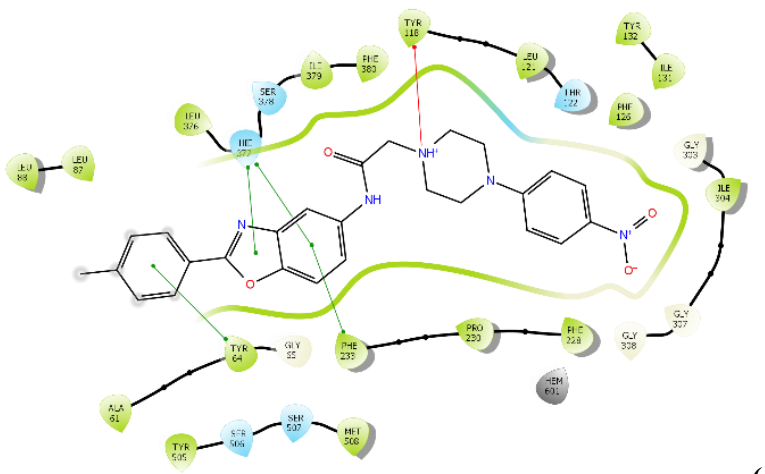

(C1)
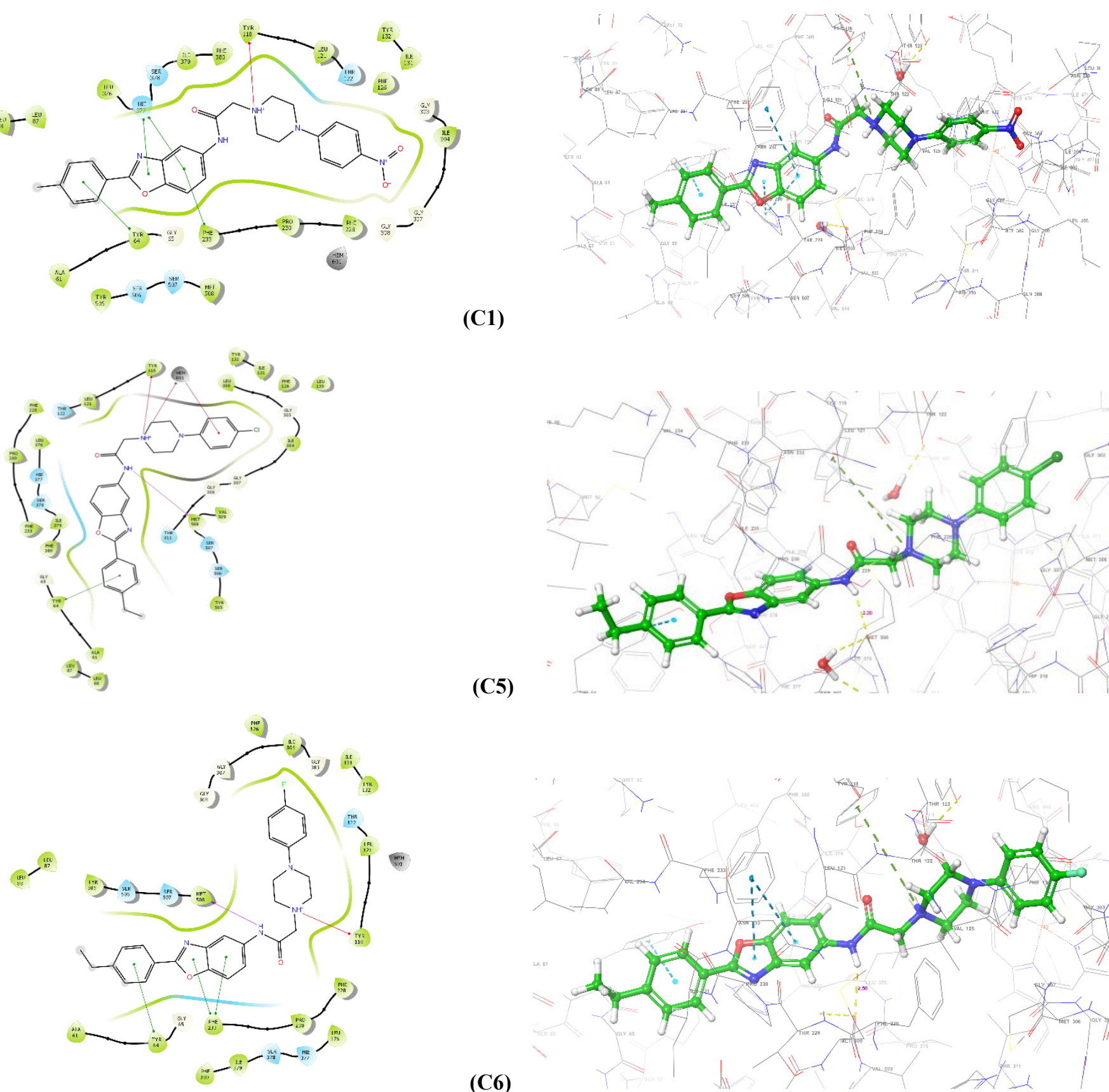

(C6)

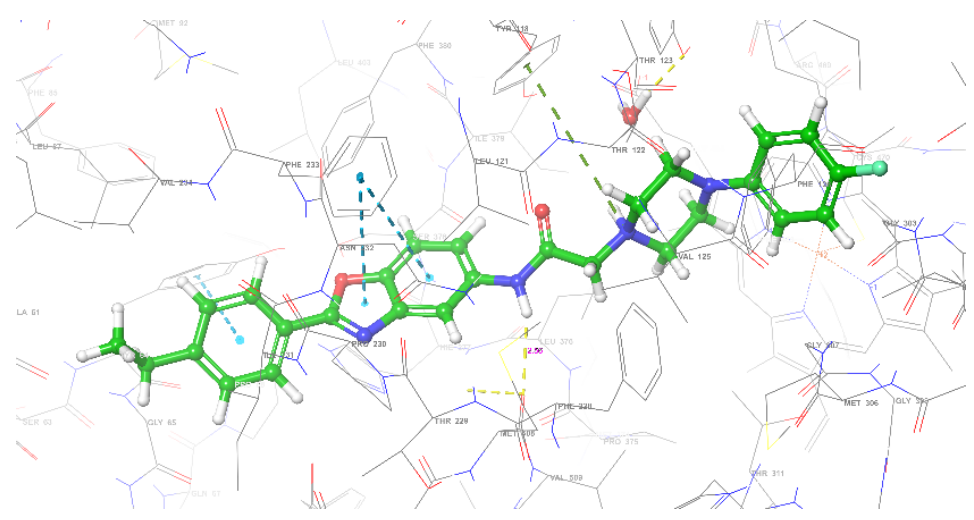

Şekil 4. CYP51 (5TZ1) aktif site ile C1, C5 ve C6 arasındaki $2 D$ ve 3D etkileşim 


\subsection{In silico ADME Tahmini}

ADME özelliklerin in silico tahmin edilmesi ilaç keşfi ve geliştirilmesinde önemli bir yer tutmaktadır. ADME özelliklerin erken değerlendirilmesi ilaç geliştirilmesinde en iyi adayların belirlenmesini ve başarılı olma ihtimali düşük olanların rededilmesini sağlayarak hem tarama hem de deneme zamanı ve harcamaları azaltmaktadır. In silico ADME modellemenin nihai amacı ilaç aday bileşiklerin insan vücudunda in vivo eğilim davranışını kinetik süreçleri birleştirerek tahmin etmektir
(Alqahtani, 2017). Tablo 4'de sentezlenen bileşiklerin lipofilik, tahmini hacim, topolojik polar yüzey alanı, yüzde absorbsiyon, moleküler ağırlık, dönebilir bağ sayısı, hidrojen bağı alıcı-verici sayısı verilmiştir. Aktif bir oral ilaç Lipinski kuralına tamamen uymalı veya bunlardan en fazla birini ihlal etmelidir (Lipinski, 2004). Absorpsiyon yüzdesi, $\% A=109-(0.345 x T P Y A)$ kullanılarak hesaplandı ve bileşikler, \% 71.73-87.74 aralığında iyi bir absorpsiyon profili gösterdi (Kilic-Kurt ve ark., 2019). Bileşiklerin bazıları Lipinski'nin Log P'sine uymadı, ancak birden fazla ihlal de yapmadi. Sonuç olarak, sentezlenen bileşiklerin farmakokinetik özelliklerinin iyi olduğu söylenebilir.

Tablo 4. Bileşiklerin teorik ADME parametreleri

\begin{tabular}{|c|c|c|c|c|c|c|c|c|c|}
\hline Bileşik No & $\underset{\leq 5}{\log P}$ & $\begin{array}{c}\text { TPYA } \\
- \\
\end{array}$ & $\begin{array}{c}\% A \\
-\end{array}$ & $\begin{array}{l}\text { MW } \\
\leq \mathbf{5 0 0}\end{array}$ & $\begin{array}{c}\mathrm{nON} \\
\leq 10\end{array}$ & $\begin{array}{c}\text { nOHNH } \\
\leq 5\end{array}$ & $\begin{array}{c}\text { İhlal Sayısı } \\
\leq 1\end{array}$ & $\begin{array}{c}\text { nrotb } \\
- \\
\end{array}$ & $\begin{array}{c}\text { Hacim } \\
-\end{array}$ \\
\hline C1 & 5.20 & 107.43 & 71.93 & 471.52 & 9 & 1 & 1 & 6 & 418.28 \\
\hline $\mathrm{C} 2$ & 4.10 & 78.68 & 81.85 & 454.53 & 7 & 1 & 0 & 5 & 413.93 \\
\hline C3 & 4.57 & 78.68 & 81.85 & 468.56 & 7 & 1 & 0 & 6 & 430.73 \\
\hline C4 & 5.66 & 107.43 & 71.93 & 485.54 & 9 & 1 & 1 & 7 & 435.08 \\
\hline C5 & 6.38 & 61.61 & 87.74 & 474.99 & 6 & 1 & 1 & 6 & 425.28 \\
\hline C6 & 5.87 & 61.61 & 87.74 & 458.54 & 6 & 1 & 1 & 6 & 416.68 \\
\hline
\end{tabular}

MA: Molekül ağırlığı. TPYA: Topolojik polar yüzey alanı. \% A: Yüzde absorpsiyon. nrotb: Dönebilen bağ sayısı. nON: Hidrojen alıcısı sayısı. nOHNH: Hidrojen vericilerinin sayısı. LogP: Log oktanol/su katsayısı

\subsection{Sınır Moleküler Yörünge Analizi}

Elektronların işgal ettiği en yüksek molekül orbitaline (HOMO) ve elektronların işgal etmediği en düşük molekül orbitaline (LUMO) sınır orbitalleri denir. HOMO, elektronlar tarafından doldurulan en dıştaki molekül yörüngesi olduğu için elektron donörü görevi görürken, LUMO elektronlarla doldurulmayan ilk boş molekül yörüngesi olduğu için elektron alıcisı olarak görev yapar. $\mathrm{Bu}$ nedenle, HOMO doğrudan molekülün iyonlaşma potansiyelini temsil ederken, LUMO molekülün elektron afinitesini temsil eder. HOMO ve LUMO arasındaki enerji boşluğu, molekülün kimyasal kararlılığının bir göstergesidir. Molekülün elektriksel yük akış özelliklerine karar vermek için kullanılan önemli bir parametredir. HOMO-LUMO arasındaki enerji farkı büyükse reaksiyon kabiliyetinin düşük olduğu yani molekülün kararlı olduğu söylenebilir. Bileşiklerin kararl11ık sirası $\mathrm{C} 3>\mathrm{C} 2>\mathrm{C} 4>\mathrm{C} 5>\mathrm{C} 6>\mathrm{C} 1$ olarak siralanır. C4'ün elektron kabul etme eğilimi yüksek iken, C6 daha fazla elektron bağışına sahiptir. Bir diğer önemli nokta ise biyolojik olarak aktif moleküllerin antimikrobiyal özelliklerini inceleyen çalışmalarda HOMO-LUMO sınır orbitallerinin önemli olmasıdır (Celik ve ark., 2020). Bir molekül Lewis asidi gibi davrandığında, gelen elektronlar LUMO'ya alınır. Düşük enerjiye sahip LUMO'lu moleküller, yüksek enerjili LUMO'lu moleküllerden daha fazla electron kabul edebilir ve bu nedenle daha yüksek aktivite gösterir. En etkili antimikrobiyal bileşiklerden biri olan $\mathbf{C 1}$ en düşük LUMO değerine sahiptir. Bütün bileşiklerin HOMOLUMO enerjileri ve bu enerjilerden elde edilen diğer elektronik özellikler (iyonizasyon potansiyeli (IP), elektron ilgisi (EA), elektronegatiflik (X), kimyasal sertlik $(\eta)$, kimyasal yumuşaklık $(\mathrm{S})$, Kimyasal potansiyeli $(\mu)$ ve elektrofilik indeksi $(\omega))$ Tablo 5 'te verilmiştir. Ayrıca C1, C5 ve C6'nın HOMO-LUMO enerjilerinin lokalize durumu Şekil 5 'te gösterilmiştir.
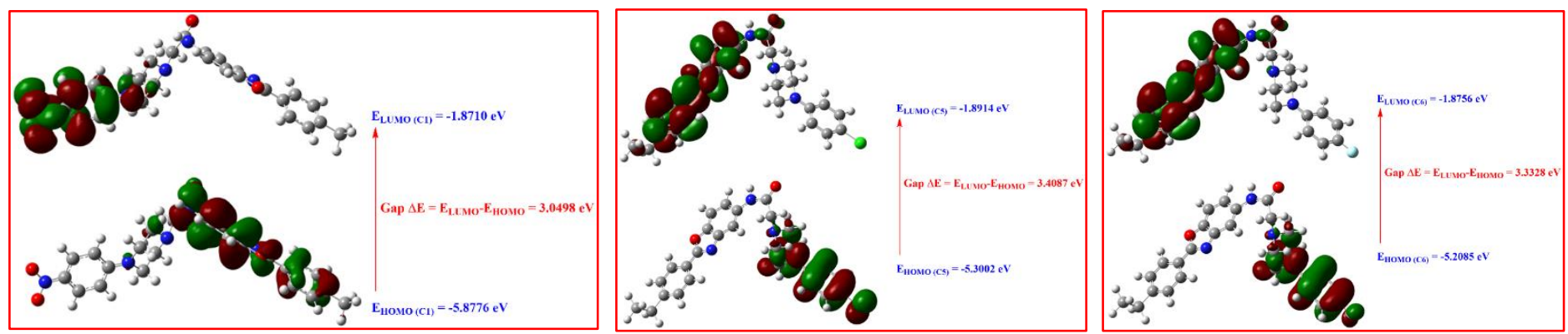

Şekil 5. C1, C5 ve C6'nın HOMO-LUMO diyagramı 
Tablo 5. C1-C6'nın hesaplanmış sınır moleküler yörünge parametreleri

\begin{tabular}{ccccccccccc}
\hline Bileșik No & HOMO & LUMO & AE & IP & EA & $\dot{\boldsymbol{\eta}}$ & $\boldsymbol{\mu}$ & $\mathbf{S}$ & $\mathbf{X}$ & $\boldsymbol{\omega}$ \\
\hline $\mathbf{C 1}$ & -5.8776 & -2.8278 & 3.0498 & 5.8776 & 2.8278 & 1.5249 & -4.3527 & 0.3278 & 3.7576 & 3.1061 \\
C2 & -5.6441 & -1.8710 & 3.7731 & 5.6441 & 1.8710 & 1.8865 & -3.7576 & 0.2650 & 3.8818 & 1.8710 \\
C3 & -6.0371 & -1.7265 & 4.3105 & 6.0371 & 1.7265 & 2.1552 & -3.8818 & 0.2319 & 4.1340 & 1.7478 \\
C4 & -6.0082 & -2.2599 & 3.7483 & 6.0082 & 2.2599 & 1.8741 & -4.1340 & 0.2667 & 3.59585 & 2.2797 \\
C5 & -5.3002 & -1.8914 & 3.4087 & 5.3002 & 1.8914 & 1.7043 & -3.5958 & 0.2933 & 3.5421 & 1.8965 \\
C6 & -5.2085 & -1.8756 & 3.3328 & 5.2085 & 1.8756 & 1.6664 & -3.5421 & 0.3000 & \#BAŞV! & 1.8822 \\
\hline
\end{tabular}

$\triangle \mathrm{E}$ : LUMO-HOMO, İP (-HOMO): İyonlaşma potansiyeli, EA (-LUMO): Elektron ilgisi, X (İP+EA)/2:

Elektronegatiflik, $\eta$ (IP-EA/)2: Kimyasal sertlik, $\mathrm{S}(1 / 2 \hat{\eta})$ : kimyasal yumuşaklık, $\mu-(\mathrm{IP}+\mathrm{EA}) / 2$ : Kimyasal potansiyel, $\omega(\mu 2 / 2 \eta)$ : Elektrofilik indeks.

\subsection{MEP Analizi}

MEP, molekül etkileşimlerini daha iyi anlamak için kullanılır ve bir molekülün çekirdeği ve elektron yük dağılımı veya toplam yük yoğunluğu hakkında önemli bilgiler sağlar. MEP; molekülün toplam yük yoğunluğu ile ilgili olduğundan, elektronegatiflik, kimyasal reaktivite, dipol moment ve kısmi yük gibi moleküler özellikler arasında ilişkiler kurar. Ayrıca; moleküllerin biyolojik özelliklerini belirlemek, hidrojen bağı etkileşimlerini belirlemek, moleküllerin kristal davranışlarını incelemek, moleküllerin korelasyonunu ve makroskopik özelliklerini geniş bir aralıkta analiz etmek ve moleküllerin elektrofilik ve nükleofilik göreli reaktivite bölgelerini tahmin etmek için kullanılır. Potansiyel artışlar kırmızı $<$ turuncu $<$ sarı $<$ yeşil $<$ mavi olarak listelenir (Mary ve ark., 2020). Kırmızı renkli kısımlar negatif elektrostatik potansiyel bölgelerini, mavi renkli kısımlar ise pozitif elektrostatik potansiyel bölgelerini temsil eder. Daha az elektron içeren bölgeler sarı ile gösterilir, yeşil renkli kısımlar elektrostatik potansiyelin sıfır olduğu bölgelerdir. C1, C5 ve C6'nın MEP haritası incelendiğinde (Şekil 6); kırmızı bölgeler esas olarak oksijen atomları üzerinde, sarı bölgeler azot, klor ve flor atomları üzerinde, mavi bölgeler ise karbon ve hidrojen atomlarının çevresinde yoğunlaşmıştır.

\subsection{Geometri Optimizasyonu}

Moleküler bir sistemin enerjisi; moleküldeki bağ uzunlukları, bağ açıları ve burulma açıları gibi parametrelerden oluşan çok değişkenli bir fonksiyondur ve bu fonksiyona Potansiyel Enerji Yüzeyi (PEY) adı verilir. PEY'de birçok minimum ve maksimum nokta vardır. Geometri optimizasyonu aynı zamanda molekülün en kararlı olduğu, yani enerjinin minimum olduğu durumları belirlemektir. Optimizasyon sonucunda molekül için hesaplanan enerji fonksiyonundan minimumlar bulunur ve bu minimumlara karşılık gelen moleküler yapıların koordinatları belirlenir. Böylelikle kuantum mekaniksel hesaplamalara başlamak için ilk koordinatlar elde edilir, çünkü molekülün en kararlı formunu bulmak için bu işlemin yapılması gerekir, aksi takdirde gereksiz etkileşimler hesaplama sonuçlarını etkileyebilir. C1, C5 ve C6'nın numaralı optimize edilmiş geometrik yapısı Şekil 6 'te verilmişstir.
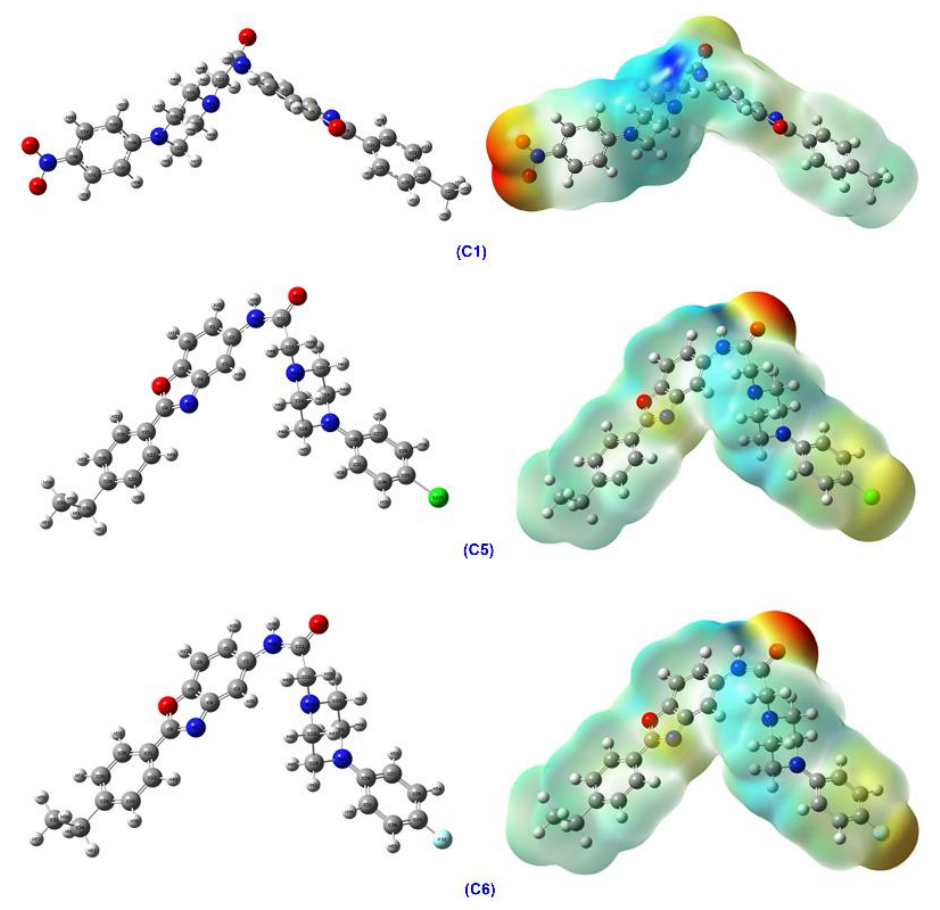

Şekil 6. C1, C5 ve C6'nın MEP haritası (sağ) ve optimize edilmiş moleküler yapısı (sol)

\section{SONUÇ}

Bu çalışma ile enfeksiyon hastalıklarına karşı mücadele için yeni ilaç etken maddesi adayı bileşiklerin keşfedilmesi ya da öncü bileşiklere ulaşmak için gerekli çalışmaların ortaya konulması amaçlanmıştır. Bu doğrultuda, bir dizi yeni 2,5-disübstitüe benzoksazol türevi bileşik sentezlenmiş ve bunların antimikrobiyal aktiviteleri incelenmiştir. Bileşikler, incelenen yapılara ve izolatlara karşı orta düzeyde bir aktivite gösterirken; C1, C5 ve C6 türevleri C. albicans izolatına karşı MIK: $16 \mu \mathrm{g} / \mathrm{mL}$ ile flukonazole oldukça yakın aktivite sergilemiştir. Tüm bileşiklerin sterol $14 \alpha$-demetilaz proteinine (CYP51) karşı moleküler doking çalışması yapıldı ve $C$. albicans izolatına karşı en etkili antimikrobiyal bileşiklerden biri olan C5'in 2D/3D protein-ligand etkileşimleri gösterildi. Tüm bileşiklerin HOMOLUMO enerjileri ve bu enerjilerden elde edilen bazı elektronik parametreleri hesapland1. C1'in en düşük LUMO değerine ve 
C3'ün en kararlı yapıya sahip olduğu gözlendi. Ayrıca C1, C5 ve C6'nın HOMO-LUMO diyagram1, MEP haritası ve optimize moleküler geometrik yapısı görsel olarak sunuldu. Bileşikler genel olarak iyi bir ADME profili gösterdi. Tüm bu sonuçlara göre, sentezlenen bileşikler yeni yapılacak çalışmalara önemli katkıda bulunmakla birlikte, özellikle C1, C5 ve C6 umut verici antifungal ajanlar olabilir.

\section{Teșekkür}

$\mathrm{Bu}$ çalışma Erciyes Üniversitesi Bilimsel Araştırma Projeleri Koordinasyon Birimi tarafından TKB-2019-9358 araştırma projesi ile desteklenmiştir. Bileşiklerin NMR analizi Erciyes Üniversitesi Teknoloji ve Araştırma Merkezi (TAUM) tarafından, HRMS analizi ise Bilkent Üniversitesi Ulusal Nanoteknoloji Araştırma Merkezi (UNAM) tarafından yapılmıştır.

\section{Kaynakça}

Abushaheen, M. A., Fatani, A. J., Alosaimi, M., Mansy, W., George, M., Acharya, S., Rathod, S., Divakar, D. D., Jhugroo, C., \& Vellappally, S. (2020). Antimicrobial resistance, mechanisms and its clinical significance. Disease-a-Month, 66(6):100971.

Alqahtani, S. (2017). In silico ADME-Tox modeling: progress and prospects. Expert opinion on drug metabolism \& toxicology, 13(11):1147-1158.

Arisoy, M., Temiz-Arpaci, O., Yildiz, I., Kaynak-Onurdag, F., Aki, E., Yalcin, I., \& Abbasoglu, U. (2008). Synthesis, antimicrobial activity and QSAR studies of 2,5-disubstituted benzoxazoles. SAR and QSAR in Environmental Research, 19(5-6):589-612.

Arisoy, M., Temiz-Arpaci, O., Kaynak-Onurdag, F., \& Ozgen, S. (2014). Synthesis and Antimicrobial Evaluation of 2-(pSubstituted Phenyl)-5-[(4-substituted piperazin-1-yl) acetamido]-benzoxazoles. Zeitschrift für Naturforschung C, 69(9-10):368-374.

Aslam, B., Wang, W., Arshad, M. I., Khurshid, M., Muzammil, S., Rasool, M. H., Nisar, M. A., Alvi, R. F., Aslam, M. A., \& Qamar, M. U. (2018). Antibiotic resistance: a rundown of a global crisis. Infection and Drug Resistance, 11:1645-1648.

Benazzouz, A., Boraud, T., Dubédat, P., Boireau, A., Stutzmann, J.-M., \& Gross, C. (1995). Riluzole prevents MPTP-induced parkinsonism in the rhesus monkey: a pilot study. European Journal of Pharmacology, 284(3):299-307.

Celik, I., Erol, M., Puskullu, M. O., Uzunhisarcikli, E., Ince, U., Kuyucuklu, G., \& Suzen, S. (2020). In Vitro and In Silico Studies of Quinoline-2-Carbaldehyde Hydrazone Derivatives as Potent Antimicrobial Agents. Polycyclic Aromatic Compounds, 1-17.

Cheminformatics, M. (2018). Calculation of molecular properties and bioactivity score. Computer software]. Retrieved from http://www. molinspiration. com/cgi-bin/properties.

Christaki, E., Marcou, M., \& Tofarides, A. (2020). Antimicrobial resistance in bacteria: mechanisms, evolution, and persistence. Journal of Molecular Evolution, 88(1):26-40.

CLSI, W. P. (2008). Reference method for broth dilution antifungal susceptibility testing of yeasts. Approved standard - third edition CLSI document M27-A3.

CLSI, C. (2018). Performance Standards for Antimicrobial Susceptibility Testing: Approved Twenty-: Document M100S28. Wayne, PA, USA: CLSI, 2018.
De Oliveira, D. M., Forde, B. M., Kidd, T. J., Harris, P. N., Schembri, M. A., Beatson, S. A., Paterson, D. L., \& Walker, M. J. (2020). Antimicrobial resistance in ESKAPE pathogens. Clinical Microbiology Reviews, 33(3): e00181-19.

Erol, M., Celik, I., Temiz-Arpaci, O., Kaynak-Onurdag, F., \& Okten, S. (2020). Design, synthesis, molecular docking, density functional theory and antimicrobial studies of some novel benzoxazole derivatives as structural bioisosteres of nucleotides. Journal of Biomolecular Structure and Dynamics, 39(9):3080-3091.

French, G. (2010). The continuing crisis in antibiotic resistance. International journal of antimicrobial agents, 36(S3-S7.

Frisch, M. (2019). Gaussian09. http://www. gaussian. com/.

GaussView, V. (2016). 6, Roy Dennington, Todd A. Keith, and John M. Millam, Semichem Inc., Shawnee Mission, KS,

Kashid, B. B., Ghanwat, A. A., Khedkar, V. M., Dongare, B. B., Shaikh, M. H., Deshpande, P. P., \& Wakchaure, Y. B. (2019). Design, Synthesis, In Vitro Antimicrobial, Antioxidant Evaluation, and Molecular Docking Study of Novel Benzimidazole and Benzoxazole Derivatives. Journal of Heterocyclic Chemistry, 56(3):895-908.

Kilic-Kurt, Z., Bakar-Ates, F., \& Bahat, M. (2019). N, N'-diaryl urea derivatives: Molecular docking, molecular properties prediction and anticancer evaluation. Journal of Molecular Structure, 1193:239-246.

Kontoyiannis, D. P., \& Lewis, R. E. (2002). Antifungal drug resistance of pathogenic fungi. The Lancet, 359(9312):11351144.

Lipinski, C. A. (2004). Lead- and drug-like compounds: the ruleof-five revolution. Drug Discovery Today: Technologies, 1(4):337-341.

Mary, Y. S., Yalcin, G., Mary, Y. S., Resmi, K., Thomas, R., Önkol, T., Kasap, E. N., \& Yildiz, I. (2020). Spectroscopic, quantum mechanical studies, ligand protein interactions and photovoltaic efficiency modeling of some bioactive benzothiazolinone acetamide analogs. Chemical Papers, 74(6):1957-1964.

Erol M., Çelik, İ., Kuyucuklu, G., \& Uzunhisarcıklı, E. (2021). Synthesis of Some New Benzoxazole Derivatives and Antimicrobial and Cytotoxic Activity Studies. Avrupa Bilim ve Teknoloji Dergisi, 21:455-462.

Oehlers, L., Mazzitelli, C. L., Brodbelt, J. S., Rodriguez, M., \& Kerwin, S. (2004). Evaluation of complexes of DNA duplexes and novel benzoxazoles or benzimidazoles by electrospray ionization mass spectrometry. Journal of the American Society for Mass Spectrometry, 15(11):1593-1603.

Osmaniye, D., Çelikateş, B. K., Sağlık, B. N., Levent, S., Çevik, U. A., Çavuşoğlu, B. K., Ilgın, S., Özkay, Y., \& Kaplancıklı, Z. A. (2021). Synthesis of some new benzoxazole derivatives and investigation of their anticancer activities. European Journal of Medicinal Chemistry, 210:112979.

Song, M. X., Huang, Y., Wang, S., Wang, Z. T., \& Deng, X. Q. (2019). Design, synthesis, and evaluation of anticonvulsant activities of benzoxazole derivatives containing the 1, 2, 4triazolone moiety. Archiv der Pharmazie, 352(8):1800313.

Taşc1, M., Temiz-Arpaci, O., Kaynak-Onurdag, F., \& Okten, S. (2018). Synthesis and antimicrobial evaluation of novel 5substituted-2-(p-tert-butylphenyl) benzoxazoles. Indian Journal of Chemistry -Section B, 57B(3):385-389.

Temiz-Arpacı, Ö., Oezdemir, A., Yalçın, İ., Yıldız, İ., Akı-Şener, E., \& Altanlar, N. (2005). Synthesis and Antimicrobial Activity of Some 5-[2-(Morpholin-4-yl) acetamido] and/or 5[2-(4-Substituted piperazin-1-yl) acetamido]-2-(p-substituted 
phenyl) benzoxazoles. Archiv der Pharmazie: An International Journal Pharmaceutical and Medicinal Chemistry, 338(2-3):105-111.

Temiz-Arpaci, O., Arisoy, M., Sac, D., Doganc, F., Tasci, M., Senol, F. S., \& Orhan, I. E. (2016). Biological evaluation and docking studies of some benzoxazole derivatives as inhibitors of acetylcholinesterase and butyrylcholinesterase. Zeitschrift Fur Naturforschung Section C-a Journal of Biosciences, 71(11-12):409-413.

Ventola, C. L. (2015). The antibiotic resistance crisis: part 1: causes and threats. $P$ T, 40(4):277-283.

Wu, Z., Bao, X.-L., Zhu, W.-B., Wang, Y.-H., Phuong Anh, N. T., Wu, X.-F., Yan, Y.-J., \& Chen, Z.-L. (2018). Design, synthesis, and biological evaluation of 6-benzoxazole benzimidazole derivatives with antihypertension activities. ACS Medicinal Chemistry Letters, 10(1):40-43. 